\title{
Elevated serum levels of macrophage migration inhibitory factor and stem cell growth factor $\beta$ in patients with idiopathic and systemic sclerosis associated pulmonary arterial hypertension
}

\author{
K. Stefanantoni' ${ }^{1}$ I. Sciarra ${ }^{1}$, M. Vasile'1, R. Badagliacca², R. Poscia², \\ M. Pendolino', C. Alessandri', C.D. Vizza ${ }^{2}$, G. Valesini ${ }^{1}$, V. Riccieri ${ }^{1}$ \\ 'Dipartimento di Medicina Interna e Specialità Mediche, UOC Reumatologia, Università La Sapienza, Roma; \\ 2Dipartimento di Scienze Cardiovascolari e Respiratorie, Università La Sapienza, Roma, Italy
}

\section{SUMMARY}

Pulmonary arterial hypertension (PAH) can be idiopathic or secondary to autoimmune diseases, and it represents one of the most threatening complications of systemic sclerosis (SSc). Macrophage migration inhibitory factor (MIF) is a pleiotropic cytokine with proinflammatory functions that appears to be involved in the pathogenesis of hypoxia-induced PH. In SSc patients, high serum levels of MIF have been associated with the development of ulcers and PAH. Stem cell growth factor $\beta$ (SCGF $\beta$ ) is a human growth factor that, together with MIF, is involved in the pathogenesis of chronic spinal cord injury. The aim of our study was to measure serum levels of MIF in patients with idiopathic and SSc-associated PAH.

We enrolled 13 patients with idiopathic PAH and 15 with SSc-associated PAH. We also selected 14 SSc patients without PAH and 12 normal healthy controls, matched for sex and age. PAH was confirmed by right hearth catheterism (mPAP> $25 \mathrm{mmHg}$ ). MIF and SCGF $\beta$ levels were measured by ELISA.

We found significantly higher circulating levels of MIF and of SCGF $\beta$ in patients with idiopathic $\mathrm{PAH}(\mathrm{P}=0.03$ and $\mathrm{P}=0.004)$ and with $\mathrm{PAH}$ secondary to $\mathrm{SSc}(\mathrm{P}=0.018$ and $\mathrm{P}=0.023)$ compared to $\mathrm{SSc}$ patients without $\mathrm{PAH}$. Higher levels of MIF were found in those patients with an higher New York Heart Association (NYHA) class ( $\mathrm{P}=0.03)$.

We can hypothesize that MIF and SCGF $\beta$ are able to play a role in PAH, both idiopathic or secondary, and in the future they may be evaluated as useful biomarkers and prognostic factors for this serious vascular disease.

Key words: Pulmonary arterial hypertension, Systemic sclerosis, Macrophage migration inhibitory factor, Stem cell growth factor $\beta$, Biomarkers.

Reumatismo, 2014; 66 (4): 270-276

\section{INTRODUCTION}

Dulmonary arterial hypertension (PAH) is an important vascular disease, potentially lethal. It's defined as the elevation of median pulmonary arterial pressure (mPAP) above $25 \mathrm{mmHg}$ with a pulmonary capillary wedge pressure $<15 \mathrm{mmHg}$ at the right hearth catheterization (1). According to the recent classification of Dana Point 2008, there are many forms of PAH. In particular we distinguish idiopathic $\mathrm{PAH}$ (iPAH) and PAH associated with connective tissue diseases (2) whereas this vascular disease is a serious complication of systemic sclerosis (SSc) (3). The pathogenesis of PAH is still unknown, but there are many evidences suggesting a role for inflammation in the vascular remodelling of the precapillary pulmonary arteries. In particular cytokines and chemokines are involved in the endothelial dysfunction, in the hypertrophy and hyperplasia of pulmonary artery smooth muscle cells (PASMCs) and in the neointima formation (4). Macrophage migration inhibitory factor (MIF) is a pleiotropic cytokine with chemokine-like functions. It has an isomerase enzymatic activity that contributes to chronic inflammation (5). It also acts as endocrine mol- 
ecule and as chaperon-like protein. MIF is expressed in a wide variety of cells in particular in immune system cells, epithelial and endothelial cells, SMC and endocrine system cells (6). MIF has many functions: it works against the immunosuppressive action of glucocorticoids, activates CXCR2 and CXCR4 dependent chemotactic responses, increases the production of pro-inflammatory cytokines such as tumour necrosis factor- $\alpha$ and inhibits the activation-induced apoptosis (7). It is also involved in the pathogenesis of atherosclerosis (8) and of many autoimmune diseases (6) and it plays a key, but controversial, role in wound repair (9). In SSc, it seems to contribute to sclerodermic vasculopathy. In fact MIF serum and tissue levels were significantly increased in SSc patients in comparison to healthy controls. In particular patients with PAH and recurrent digital ulcers showed higher MIF levels than patients without these manifestations (10, 11).

Besides, a particular genetic polymorphism, MIF-173 promoter polymorphism, is associated with the diffuse form of SSc $(12,13)$. Recent evidences show a role of MIF in the pathogenesis of hypoxiainduced $\mathrm{PH}$ with higher levels in patients with idiopathic and with interstitial lung disease associated $\mathrm{PH}$ respect to healthy controls (14). MIF may induce the proliferation of PASMCs and may enhance the vasoconstriction of pulmonary arteries in murine models and in human in vitro models $(15,16)$. Because of its role of mediator of pathogenic mechanisms in many systemic and organ-specific autoimmune diseases, neutralizing the action of endogenous MIF with monoclonal antibodies or small chemical inhibitors of its tautomerase activity, such as ISO-1, may be effective in the control of several models of autoimmune diseases $(6,7)$.

Stem cell growth factor (SCGF) is a human growth factor for hematopoietic progenitor cells, which belongs to the C-type lectin superfamily (17). There are two isoforms $(\alpha$ and $\beta$ ) and SCGF $\beta$ exhibits a burst-promoting activity and granulocyte/ macrophage colony stimulating activity on erythroid and granulocyte/macrophage progenitor cells (18). It seems to have a prognostic role in Chagas' disease and idiopathic dilated cardiomyopathy (19). Its serum levels seem to increase following stem cell transplantation (20), and together with MIF, it is involved in the pathogenesis of chronic spinal cord injury (21). No data are actually available concerning its role in $\mathrm{SSc}$ and in PAH.

\section{MATERIALS AND METHODS}

\section{Objectives}

We dosed MIF and SCGF $\beta$ serum levels in patients affected by PAH, both idiopathic and secondary to SSc, to determine their potential role in the development of this important vascular disease and any potential difference between the two forms of PAH.

\section{Methods}

We enrolled 13 consecutive patients affected by iPAH who had been referred to the Pulmonary Hypertension Center of our Hospital and 15 consecutive patients referred to our Rheumatology Unit affected by the SSc-associated form of PAH. As controls we enrolled 14 patients affected by SSc without PAH and 12 normal healthy controls (NHC) sex and age matched. SSc patients were classified according the American College of Rheumatology (ACR) classification criteria of 1980 (22) and the classification was confirmed with the new ACR/European League Against Rheumatism (EULAR) Criteria of 2013 (23). The diagnosis of PAH was confirmed by right hearth catheterization and it was defined as a precapillary pulmonary hypertension (mPAP > $25 \mathrm{mmHg}$, pulmonary wedge pressure $<15 \mathrm{mmHg}$ ) (1). All patients underwent to clinical and laboratory evaluation, including the assessment of the New York Heart Association (NYHA) functional class. SSc patients organ involvement was defined as previously described (24): lung = bibasilar pulmonary fibrosis on chest radiography; isolated $\mathrm{PH}=$ clinical evidence of $\mathrm{PH}$ and increased systolic pulmonary ar- 
terial pressure $(>35 \mathrm{mmHg})$, indirectly assessed by echocardiography, in the absence of severe pulmonary interstitial fibrosis; oesophagus $=$ hypomotility shown by barium radiography; joint $=$ inflammatory polyarthralgias or arthritis; heart $=$ pericarditis, congestive heart failure, or arrhythmias requiring treatment. High-resolution computed tomography was performed in each case showing negative $\mathrm{x}$-ray and the diagnosis of pulmonary fibrosis was done by a radiologist, blinded reading, basing on the presence either of bilateral basilar reticulonodular changes on x-ray or of ground glass appearance of the lung parenchyma on HRTC. The cutaneous evaluation included: presence/absence of Raynaud's phenomenon, modified Rodnan skin score (25), presence/absence of digital ulcers, defined as a loss of epithelialization and tissues involving the epidermis, the dermis and the subcutaneous tissue, teleangiectasia, calcinosis, defined as deposits of calcium in soft tissues eye visible or confirmed by $\mathrm{x}$-ray (26). All patients underwent a nailfold videocapillaroscopy as previously described (27). Antinuclear antibodies including anti-centromere antibodies were detected by indirect immunofluorescence using HEp-2 cell line as substrate (Bio-Rad Lab., Hercules, CA, USA). Antibodies against topoisomerase I (anti-Scl70) were measured using enzyme-linked immunosorbent assays (ELISA) (Diamedix, Miami, FL, USA). Serum sample was obtained from all patients and sera were stored at $-20^{\circ} \mathrm{C}$. Levels of MIF and SCGF $\beta$ were detected by enzyme-linked immunoassay (Bio-Rad
Lab.). Assays were performed following the manufacturer's instructions.

\section{Statistical analysis}

The Mann-Whitney U test was used for comparison of groups. For correlation analysis, Spearman's rank correlation test was employed. $P$ values $\leq 0.05$ were considered significant.

\section{RESULTS}

All SSc patients were female, 15 with PAH (mean age 67 yrs, range 50-75; mean disease duration 230 months; range 4-696) and 14 without PAH (mean age 62.5 yrs, range 47-79; mean disease duration 154.6 months, range 84-502). Among those patients with PAH, 10 had the limited form of SSc and 5 had the diffuse form, the mean mRSS was 13 (range 4-30), 2 had digital ulcers, 5 were anti-centromere positive and 1 anti-Scl70 positive, while in the group without PAH, 12 had the limited form and 2 had the diffuse form, the mean mRSS was 11 (range 4-24), 4 had digital ulcers, 10 were anti-centromere positive and 4 anti-Scl70 positive (Tab. I). The 13 patients with iPAH were 9 female and 4 male (mean age $=55.7$ yrs; mean disease duration $=$ $5.48 \mathrm{yrs}$ ) and the $12 \mathrm{NHC}$ were sex and age matched.

We found significantly higher circulating levels of MIF and of SCGF $\beta$ in patients with idiopathic PAH (MIF median $270 \mathrm{pg} / \mathrm{mL}$ vs $175 \mathrm{pg} / \mathrm{mL}, \mathrm{P}=0.03$; SCGF $\beta$ median $18,845 \mathrm{pg} / \mathrm{mL}$ vs $12,054 \mathrm{pg} /$

Table I - Main clinical-demographic and laboratory features of systemic sclerosis (SSc) patients, with and without pulmonary arterial hypertension (PAH).

\begin{tabular}{|l|l|l|l|}
\hline & SSc patients without PAH (n=14) & $\begin{array}{l}\text { Patients with SSc-associated } \\
\text { PAH }(\mathbf{n}=15)\end{array}$ & P \\
\hline Sex (F) & 14 & 15 & n.s. \\
\hline Mean age (range) & 62.5 yrs (47-79) & 67 yrs (50-75) & n.s. \\
\hline Mean disease duration (range) & 154.6 months (84-502) & 230 months (4-696) & n.s. \\
\hline Form (L/D) & $12 / 2$ & $10 / 5$ & n.s. \\
\hline Mean mRSS (range) & $11(4-24)$ & $13(4-30)$ & n.s. \\
\hline Digital ulcers (n. pt.) & $4(28.5 \%)$ & $2(13 \%)$ & n.s. \\
\hline Anti-centromere+ve & $10(71 \%)$ & $5(33 \%)$ & n.s. \\
\hline Anti-topoisomerase1+ve & $4(29 \%)$ & $1(7 \%)$ & n.s. \\
\hline
\end{tabular}


$\mathrm{mL}, \mathrm{P}=0.004)$ and $\mathrm{SSc}$-associated $\mathrm{PAH}$ (MIF median $333 \mathrm{pg} / \mathrm{mL}$ vs $175 \mathrm{pg} / \mathrm{mL}$, $\mathrm{P}=0.018$; SCGF $\beta$ median $17,804 \mathrm{pg} / \mathrm{mL}$ vs $12,054 \mathrm{pg} / \mathrm{mL}, \mathrm{P}=0.023$ ) compared to SSc patients without PAH (Tab. II and III; Fig. 1 and 2). We found higher mean levels of MIF and SCGF $\beta$ in SSc patients, in particular in those with $\mathrm{PAH}$, and in patients with iPAH compared to normal control but the differences were not sta-

Table II - Macrophage migration inhibitory factor (MIF) and stem cell growth factor (SCGF) b serum levels $(\mathrm{pg} / \mathrm{mL})$ in patients with idiopathic pulmonary arterial hypertension (PAH) and in systemic sclerosis (SSc) patients without PAH (SSc controls) (median \pm standard deviation).

\begin{tabular}{|l|l|l|l|}
\hline & iPAH & SSc controls & P \\
\hline MIF & $270 \pm 636.2$ & $175 \pm 68.68$ & 0.03 \\
\hline SCGF $\beta$ & $18,845 \pm 5819.7$ & $12,054 \pm 3448.5$ & 0.004 \\
\hline
\end{tabular}

Table III - Macrophage migration inhibitory factor (MIF) and stem cell growth factor (SCGF) $\beta$ serum levels $(\mathrm{pg} / \mathrm{mL})$ in patients with systemic sclerosis (SSc)-associated pulmonary arterial hypertension (PAH) and in SSc patients without PAH (SSc controls) (median \pm standard deviation).

\begin{tabular}{|l|l|l|l|}
\hline & $\begin{array}{l}\text { SSc-associated } \\
\text { PAH }\end{array}$ & SSc controls & P \\
\hline MIF & $333 \pm 520$ & $175 \pm 68.68$ & 0.018 \\
\hline SCGF $\beta$ & $17,804 \pm 8033.2$ & $12,054 \pm 3448.5$ & 0.023 \\
\hline
\end{tabular}

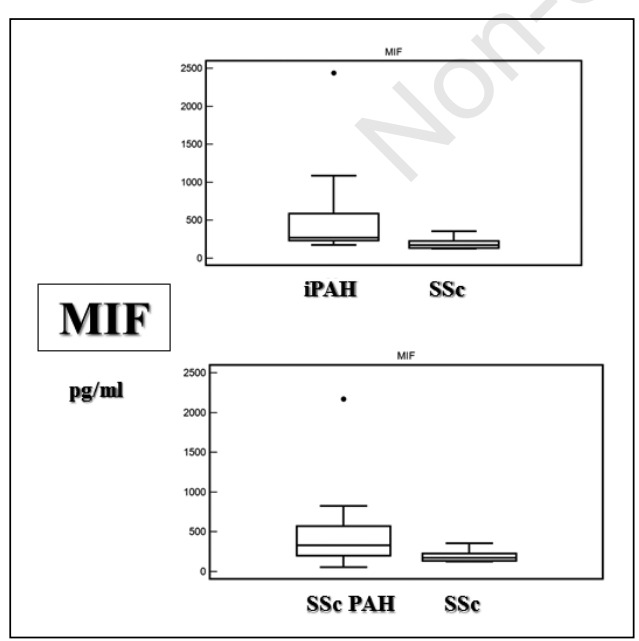

Figure 1 - Macrophage migration inhibitory factor (MIF) serum levels $(\mathrm{pg} / \mathrm{mL}$ ) in patients with idiopathic pulmonary arterial hypertension (iPAH) and systemic sclerosis (SSc)-associated $\mathrm{PAH}(\mathrm{P}=0.03$ and $\mathrm{P}=0.018)$. tistically significant. We didn't find any significant difference between the two forms of PAH and regarding other vascular manifestations such as digital ulcers and nailfold capillaroscopy features. Besides we found a significant increase of MIF levels in patients with an higher NYHA functional classes (class NYHA 3-4 vs class NYHA 1-2) (median 380.69 $\mathrm{pg} / \mathrm{mL}$ vs $244.58 \mathrm{pg} / \mathrm{mL}, \mathrm{P}=0.03$ ) (Fig. 3). We didn't find any significant correlation between MIF and SCGF $\beta$ and other clinical or laboratory parameters.

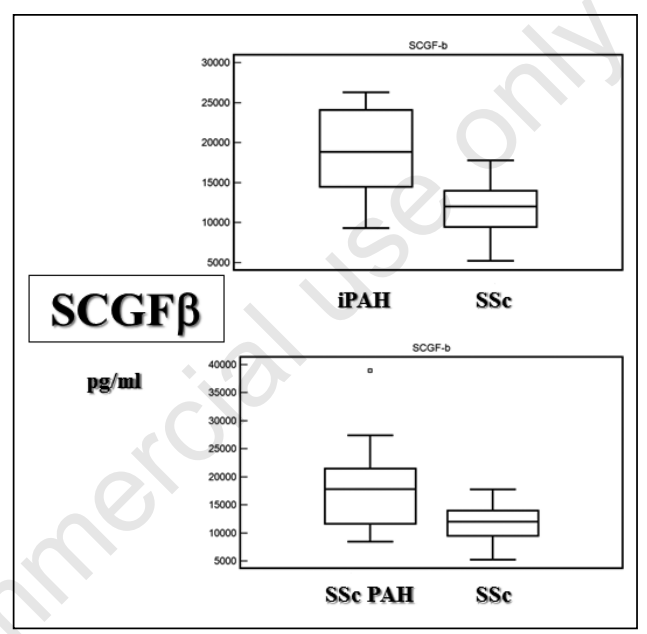

Figure 2 - Stem cell growth factor (SCGF) $\beta$ serum levels $(\mathrm{pg} / \mathrm{mL}$ ) in patients with idiopathic pulmonary arterial hypertension (iPAH) and systemic sclerosis (SSc)-associated PAH $(\mathrm{P}=0.04$ and $\mathrm{P}=0.023)$.

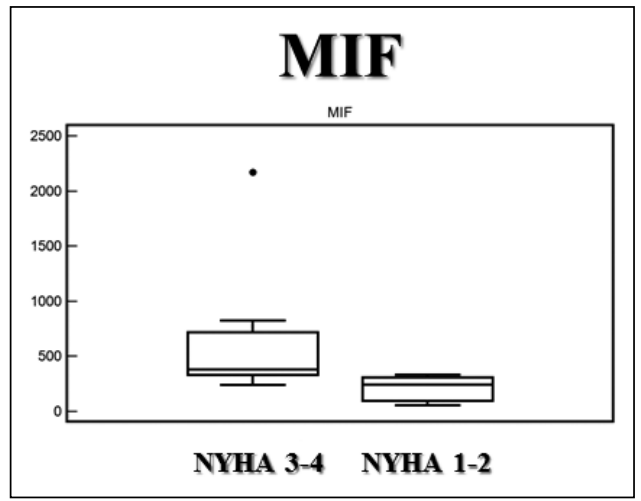

Figure 3 - Macrophage migration inhibitory factor (MIF) serum levels $(\mathrm{pg} / \mathrm{mL}$ ) in patients with the New York Heart Association (NYHA) functional classes 3-4 and NYHA functional classes 1-2 ( $P=0.03)$. 


\section{CONCLUSIONS}

PAH is an important vascular disease, potentially lethal and it can be associated with connective tissue diseases (2). MIF is a pleiotropic cytokine and in SSc patients, serum levels of MIF are increased compared to healthy controls and have been associated with the development of ulcers and PAH (11). Moreover, MIF seems to be involved in the pathogenesis of hypoxiainduced $\mathrm{PH}$, showing higher levels in those patients with idiopathic $\mathrm{PH}$ and with interstitial lung disease-associated $\mathrm{PH}$ respect to healthy controls (14). SCGF $\beta$ seems to have a prognostic role in Chagas' disease and idiopathic dilated cardiomyopathy (19) and together with MIF, is involved in the pathogenesis of chronic spinal cord injury (21). In our study, we found significantly higher levels of MIF and SCGF $\beta$ in patients with $\mathrm{PAH}$ and $\mathrm{SSc}$-associated $\mathrm{PAH}$, without any significant difference between the two forms of PAH. Regarding MIF, unlike other studies (11), we didn't found any significant association with the other clinical manifestation of SSc vasculopathy, such as digital ulcers. In a previous study, we found a significant association between a more severe capillaroscopic score and the presence of PAH (28). Instead, in this study, we didn't find any significant association between the serum levels of MIF and SCGF $\beta$ and the nailfold capillaroscopic features. Like previous study $(10,11)$, we found higher mean levels of MIF and SCGF $\beta$ in SSc patients, in particular in those with $\mathrm{PAH}$, and in patients with $\mathrm{PAH}$, compared to normal control but the differences were not statistically significant, probably because of the small sample size. Thus, the higher serum levels of MIF seem, in our cohort of patients, to be specific of PAH and these data are consistent with the recent evidences for a role of MIF as a molecular mediator in the pathogenesis of $\mathrm{PH}$ in murine and human in vitro models $(15,16)$. No data are actually available regarding the SCGF $\beta$ involvement in $\mathrm{PAH}$ and in SSc pathogenesis. SCGF $\beta$ has been studied as a prognostic factor in other kinds of cardiovascular diseases (19).
Thus our study presents for the first time an association among this molecule, $\mathrm{PAH}$ and SSc. Because of the potential lethality of PAH, there is a need of sensible diagnostic tools to early assess the development of this important vascular disease. The next step of our research will be to verify the real sensibility of these molecules.

We also found that significantly higher serum levels of MIF, but not of SCGF $\beta$ are present in patients with higher NYHA functional classes (NYHA 3 and 4) probably reflecting a more severe vascular damage and, consequently, a more severe type of PAH. Thus MIF seems to behave as a prognostic marker, to be used for monitoring patients with PAH. Our study confirms the association of MIF, a proinflammatory cytokine, with PAH and these results are consistent with the evidence that suggests a role for inflammation in the vascular remodelling of the precapillary pulmonary arteries, that are among the main features of the pathogenetic mechanism of PAH (4). To establish the possible role of MIF in the pathogenesis of PAH, both idiopathic and secondary, may have important consequences in the current therapeutic strategy for PAH (1). In fact monoclonal antibodies directed against MIF or small chemical inhibitors of its tautomerasic activity, such as ISO-1, are already experienced in many models of autoimmune diseases $(6,7)$.

In conclusions, with our study we can hypothesize a role for MIF and SCGF $\beta$ as biomarkers of PAH and, for MIF in particular, as a prognostic marker.

Further studies are needed to identify a clear pathogenetic role for these molecules in the development of PAH, as well as their potential use as therapeutic targets.

Competing interest: none declared

\section{REFERENCES}

1. Galiè N, Hoeper MM, Humbert M, Torbicki A, Vachiery JL, Barbera JA, et al. Guidelines for the diagnosis and treatment of pulmonary hypertension. The Task Force for the Diagnosis and Treatment of Pulmonary Hypertension of the European Society of Cardiology (ESC) 
and the European Respiratory Society (ERS), endorsed by the International Society of Heart and Lung Transplantation (ISHLT). Eur Heart J. 2009; 30: 2493-37.

2. Simonneau G, Robbins IM, Beghetti M, Channick RN, Delcroix M, Denton CP, et al. Updated clinical classification of pulmonary hypertension. J Am Coll Cardiol. 2009; 54: S43-54.

3. Shahane A. Pulmonary hypertension in rheumatic diseases: epidemiology and pathogenesiss. Rheumatol Int. 2013; 33: 1655-67.

4. Price LC, Wort SJ, Perros F, Dorfmüller P, Huertas A, Montani D, et al. Inflammation in pulmonary arterial hypertension. Chest. 2012; 141: 210-21.

5. Cooke G, Armstrong ME, Donnelly SC. Macrophage migration inhibitory factor (MIF), enzymatic activity and the inflammatory response. Biofactors. 2009; 35: 165-8.

6. Stosic-Grujicic S, Stojanovic I, Nicoletti F. MIF in autoimmunity and novel therapeutic approaches. Autoimmun Rev. 2009; 8: 244-9.

7. Bucala R. MIF, MIFAlleles, and prospects for therapeutic intervention in autoimmunity. J Clin Immunol. 2013; 33: S72-8.

8. Asare Y, Schmitt M, Bernhagen J. The vascular biology of macrophage migration inhibitory factor (MIF). Expression and effects in inflammation, atherogenesis and angiogenesis. Thromb Haemost. 2013; 109: 391-8.

9. Gilliver SC, Emmerson E, Bernhagen J, Hardman MJ. MIF: a key player in cutaneous biology and wound healing. Experimental Dermatol. 2011; 20: 1-6.

10. Selvi E, Tripodi SA, Catenaccio M, Lorenzini S, Chindamo D, Manganelli S, et al. Expression of macrophage migration inhibitory factor in diffuse systemic sclerosis. Ann Rheum Dis. 2003; 62: 460-4.

11. Becker H, Willeke P, Schotte H, Domschke W, Gaubitz M. Macrophage migration inhibitory factor may contribute to vasculopathy in systemic sclerosis. Clin Rheumatol. 2008; 27 : 1307-11.

12. Wu SP, Leng L, Feng Z, Liu N, Zhao H, McDonald C, et al. Macrophage migration inhibitory factor promoter polymorphisms and the clinical expression of scleroderma. Arthritis Rheum. 2006; 54: 3661-9.

13. Bossini-Castillo L, Simeon CP, Beretta L, Vonk MC, Callejas-Rubio JL, Espinosa G, et al. Confirmation of association of the macrophage migration inhibitory factor gene with systemic sclerosis in a large European population. Rheumatology (Oxford). 2011; 50: 1976-81.

14. Zhang Y, Talwar A, Tsang D, Bruchfeld A, Sadoughi A, Hu M, et al. Macrophage migration inhibitory factor mediates hypoxiainduced pulmonary hypertension. Mol Med. 2012; 18: 215-23.
15. Zhang B, Luo Y, Liu ML, Wang J, Xu DQ, Dong MQ, et al. Macrophage migration inhibitory factor contributes to hypoxic pulmonary vasoconstriction in rats. Microvasc Res. 2012; 83: 205-12.

16. Zhang B1, Shen M, Xu M, Liu LL, Luo Y, Xu $\mathrm{DQ}$, et al. Role of macrophage migration inhibitory factor in the proliferation of smooth muscle cell in pulmonary hypertension. Mediators Inflamm. 2012; 2012: 840737.

17. Hiraoka A, Sugimura A, Seki T, Nagasawa T, Ohta N, Shimonishi M, et al. Cloning, expression, and characterization of a cDNA encoding a novel human growth factor for primitive hematopoietic progenitor cells. Proc Natl Acad Sci USA. 1997; 94: 7577-82.

18. Mio H, Kagami N, Yokokawa S, Kawai H, Nakagawa S, Takeuchi K, et al. Isolation and characterization of a cDNA for human mouse, and rat full-length stem cell growth factor, a new member of C-type lectin superfamily. Biochem Biophys Res Commun. 1998; 249: 124-30.

19. Wang Y, Khan A, Heringer-Walther S, Schultheiss HP, Moreira Mda C, Walther T. Prognostic value of circulating levels of stem cell growth factor $\beta$ (SCGF $\beta$ ) in patients with Chagas' disease and idiopathic dilated cardiomyopathy. Cytokine. 2013; 61: 728-31.

20. Ito C, Sato H, Ando K, Watanabe S, Yoshiba F, Kishi K, et al. Serum stem cell growth factor for monitoring hematopoietic recovery following stem cell transplantation. Bone Marrow Transplant. 2003; 32: 391-8.

21. Stein A, Panjwani A, Sison C, Rosen L, Chugh R, Metz C, et al. Pilot study: elevated circulating levels of the proinflammatory cytokine macrophage migration inhibitory factor in patients with chronic spinal cord injury. Archiv Phys Med Rehab. 2013; 94: 1498-507.

22. [No authors listed]. Preliminary criteria for the classification of systemic sclerosis (scleroderma). Subcommittee for scleroderma criteria of the American Rheumatism Association Diagnostic and Therapeutic Criteria Committee. Arthritis Rheum. 1980; 23: 581-90.

23. van den Hoogen F, Khanna D, Fransen J, Johnson SR, Baron M, Tyndall A, et al. 2013 classification criteria for systemic sclerosis: an American College of Rheumatology/European League against Rheumatism collaborative initiative. Arthritis Rheum. 2013; 65: 2737-47.

24. Steen VD, Powell DL, Medsgert TA JR. Clinical correlations and prognosis based on serum autoantibodies in patients with systemic sclerosis. Arthritis Rheum. 1988; 31: 196-203.

25. Kahaleh MB, Sultany GL, Smith EA, Huffstutter JE, Loadholt CB, LeRoy EC. A modified scleroderma skin scoring method. Clin Exp Rheumatol. 1986; 4: 367-9.

26. Amanzi L, Braschi F, Fiori G, Galluccio F, 
Miniati I, Guiducci S, et al. Digital ulcers in scleroderma: staging, characteristics and subsetting through observation of 1614 digital lesions. Rheumatology. 2010; 49: 1374-82.

27. Cutolo M, Sulli A, Pizzorni C, Accardo S. Nailfold videocapillaroscopy assessment of microvascular damage in systemic sclerosis.
J Rheumatol. 2000; 27: 155-60.

28. Riccieri V, Vasile M, Iannace N, Stefanantoni K, Sciarra I, Vizza CD, et al. Systemic sclerosis patients with and without pulmonary arterial hypertension: a nailfold capillaroscopy study. Rheumatology (Oxford). 2013; 52: 1525-8. 